\title{
Becoming a doctor
}

Sarah Elise Finlay and Monica Fawzy University of Bristol

\begin{abstract}
Medical training cannot be equated with merely studying for a degree. It encompasses much more, challenging one's values, self perception and perspective on life itself. During five years at medical school, the individual irreversibly alters to become "a medic", not just "a student of medicine", no matter how much detachment from the course and its associated lifestyle the individual has endeavoured to preserve. In the following article, we intend to explore the different stages of training and discuss how each shapes the student. "Becoming a medic" intellectually, emotionally and spiritually is the inevitable consequence of spending five years at medical school, and the assumption of this role is indeed crucial to survival in medical practice. The importance of bringing our own individual qualities to the profession must, however, not be overlooked. Personal flair and abilities should be nurtured, not suppressed during medical school. A diversity of interests serves both to ease the pressures laid upon us at medical school, and to broaden our characters and deepen our understanding of humanity. Medical students, while necessarily adapting to the role of a doctor, should emerge from their training not as narrow "medics" but as enthusiastic, compassionate people equipped to treat patients to the best of their ability.

(F Med Ethics: Medical Humanities 2001;27:90-92)
\end{abstract}

Keywords: Medical students; medical training; medical school

First year medical students are very diverse. People choose to study medicine for reasons as diverse as the individuals themselves. Their parents may be doctors, in which case the child is brought up surrounded by medical jargon; for them, medicine is "the norm". Financial and job security, social prestige, altruism, pure interest, seeking a challenge ... different motivators bring together the hundred or so expectant students sitting in the first year medical school lecture theatre on the first day of freshers' week. Looking around on that day, you know that amongst these strange individuals will be lifelong friends, a support network, and some rivals. We remember being completely in awe of our peers as they recited the impressive achievements in academia, in the arts, in sport, which clinched their places here. An air of confidence and arrogance, laced with fear, emanated from the group. A collage of different people with different expectations, values and backgrounds start the five-year process of changing to become doctors.
Despite the initial diversity, many candidates are similar in that they experienced a subtle yet significant change in attitude towards them resulting from their decision to apply for medicine. Coping should be innate in a medical school applicant. No longer can you wince when cutting open a pig's eye in A level biology, nor display even a trace of squeamishness if faced with flesh and blood after a sports field injury. On the contrary, one is subject to an implied obligation to run to the victim's aid and know (or at least confidently feign knowledge of) exactly how to handle any incident. Applying for medicine casts you as one of the more responsible, diligent and intelligent in your year, which itself brings an implicit pressure to live up to that image. Any underachievement, or mere failure to excel, is glaringly spotlighted by the incandescent knowledge that the course for which you are applying has such dauntingly competitive entry criteria. Thus, right from the moment a student suggests he or she go for a place at medical school, the realisation that medicine is not just another degree filters in. Already your own and other people's perceptions of you are altering.

Few people really know what is expected of them, or how they should adapt to their new role as "medical students" as they enter medical school, but many have an idea. A factual anecdote serves to highlight this point. Following coffee break on the first day of freshers' week, a "house officer" stormed into the lecture theatre, doors flapping wildly in his wake. He barked that he was the "welfare and discipline representative", and we'd better jolly well listen to what he had to say: "Now you are medics! You are different from other students at this university. One day you will be doctors and you are expected to behave accordingly. As from now you will dress smartly and conservatively. You will always be punctual. You are expected to work harder than you have ever worked before. Remember at all times that you are setting an example.... Think hard about this before you smoke, drink or indulge in any forms of risky behaviour!' It is noteworthy that a good many of us were completely taken in by this spoof. Demands such as those above could, just could, have been real.

Medical training is so demanding of time and energy compared with many other university courses (we had on average four lectures a day with practical sessions/tutorials in the afternoon when various friends often considered whether it would be worthwhile attending their twice weekly eleven o'clock seminars), that medical students tend to flock together. Copious amounts of time spent by non-medical friends musing over coffees and 
student politics, art or current affairs whizzes by for the more pressurised medics. They are busy making snap decisions about who will volunteer to be the subject for the forthcoming "urine output", or have electric shocks spiked up their right arm to educate their peers about the ulnar nerve. "Work hard, play hard" is the ethos. It was no surprise to us to learn that a recent study revealed that $52.6 \%$ of male and $50.6 \%$ of female medical students drank to excess of the recommended 21 units for men and 14 units for women per week, while $28.3 \%$ of male and $35.6 \%$ of female medical students reported the illicit use of drugs. ${ }^{1}$ There is a marked social pressure to live up to the "crazy medic" image, which was an intimidating strain for many previously unexposed to such a culture. The choice was laid bare: sink or swim. Become a "medic", go to the medics' bar, laugh about rectal examinations and vomit, wear theatre blues to bed, play contact sports and jolly well down that pint, or have a lot less fun and, more damagingly, be less accepted.

In compensation, the social network can be extremely supportive. Few other faculties have a complete lifestyle associated with them: their own sports clubs, reviews, regular social events, international student network (MedSin) and magazines. This adds to the "buzz" of being part of a medical school, and creates a sense of community and belonging, reducing some of the anxiety engendered by the course. Medical school thus determines to a marked extent the student's social interactions, particularly in the final part of the course when non-medical friends have graduated and medics are the insulated crowd left with whom to socialise. Peer influence is strong stuff; few would claim that five years at medical school had not altered their behaviour and fashioned their character to some extent.

Non-medical friends' influence is also strong; many other students view medical students not only negatively, as "cliquey" and exclusive, but also in a positive light as knowledgeable and able to give sound advice about health issues. Friends have sought advice about personal anxieties ranging from running noses to suspected liver failure after the freshers' ball, or a boyfriend's impotence. Although standard advice was inevitably along the lines of "if it doesn't improve go to the student health service," friends seemed generally willing to trust what we said. Our "medical" opinions were taken seriously, bringing a responsibility to give sound advice; thus the process of becoming a doctor accelerated.

This feeling of responsibility increases as we move through pre-clinical to clinical years, having a marked impact on the way we learn. As with other degree courses, we are stretched intellectually to accumulate all the mounds of information heaped upon us; however, as medical students we must also make the psychological adjustment from learning for the sake of learning, or passing exams, to learning in order to eradicate those gaps in our knowledge that could mean disastrous mistakes in clinical practice. This was starkly pointed out in a postexamination evaluation session when a lecturer reminded us that the consequence of not mastering our knowledge could be the death of a patient.

The reality of death is thrust at us as medical students. From the moment we swung through the doors of the dissection room (DR) in the first year, we were faced with the immensity of what we will have to cope with during our studies and professional lives. Members of the medical profession are among the few legally permitted to handle cadavers. ${ }^{2}$ Dealing with dead bodies involves legal, moral, social and even religious taboos, which we traverse at the tender age of eighteen. As our minds grappled with this new situation, the involvement of our senses heightened its reality; the smell of formaldehyde permeated our clothes and hair, appetites suffered and some admitted that the sights of the DR remained vivid in their sleep. Despite having been personally affected, everyone fought to put on a brave face, feigning indifference. Because we did not and still do not understand death and what it involves, we did not know how to react to the bodies, or deal with the horrific thought that we were cutting up human flesh. During our first session, the anatomy demonstrator casually threw a pile of books down on our group's cadaver, making us flinch: this was the first time that the body was treated as an object in our presence, thus paving the way to the depersonalisation of the cadavers. Three months later, we had managed to distance ourselves from the morbid nature of anatomy sessions. However, the experience still haunted us: I remember attending a family party after the "upper limb session" and being unable to look at the hands of my relatives without imagining them disembodied in the dissecting room. This may sound melodramatic, but the profound impact of the dissection room sessions should not be underestimated. They are the first bridge leading us away from the lay public towards the medical world. Such exposure irreversibly alters our perception of the human fabric, and instils in us the understanding of the importance of emotional distance from what we see before us; crucial for coping when faced with pain, suffering and death of patients.

As a coping mechanism, it is inevitable in the clinical years that one distances oneself to some extent from patients as people, seeing them more as "cases of disease". When we first encountered patients, I remember thinking that the ill were already sufficiently inconvenienced; the hassle of talking to us was the last thing they needed. At that stage, we thought we had nothing to offer them, since our medical knowledge was negligible. Progressing through the course, these people became our educational resource, providing us with the essential symptoms and signs we needed to recognise in order to pass the increasingly regular exams. Pristine white coats and that ultimate status symbol, a Littman stethoscope, act as a uniform to shield us emotionally from the suffering around us. A new etiquette is learnt as strangers happily strip clothes off in front of you and allow you to perform 
unpleasant intimate examinations; there is a certain voyeurism intrinsic to this training, and perceiving ill people primarily as patients is a way of accepting it. As we have gained medical knowledge, we have lost a degree of lay empathy; our reaction when faced with a new patient is not to feel sorrow but to jump to eliciting clues to the diagnosis.

As medical students, we are constantly aware of pressures upon, and negative attitudes towards, the profession we are training to enter. The demoralising effects for students are marked: the image held by many who entered medical school of idealistic doctors healing the sick and of being compassionate and respected members of the community has been shattered. Now we are aware that the medical world which lies ahead is one of legal battles, business disputes and economics. A total of 7,640 medical legal cases and 224,462 medicolegal telephone enquiries were dealt with in 1999 by the Medical Protection Society. ${ }^{3}$ Pressures upon the medical student mount as we realise that much of being a doctor is centred around keeping not only patients but also their lawyers satisfied. Survival as a doctor needs a wide range of skills, one of the greatest of which (we now realise as our time at medical school draws to a close) is an ability to cope not only with patient issues but also with such pressures from the outside world.

One way of dealing with pressure is the pursuit of outside interests, but these are all too often quashed during medical-school life. For many, the whole prospect of becoming a doctor is enough of an achievement and goal, so other talents are no longer cultivated and many are forgotten. How many in our year have stifled their talents in art, music and drama, not simply because of time pressures but because they were viewed as superfluous to a new found role? The attitudes of some seniors in the profession have implied that medicine should be our life; any outside interests should be sidetracked rather than allowed to flourish. And for many this has happened; a combination of time pressures and lack of enthusiasm to cultivate other interests has meant they have become narrower people during their time at medical school, their perception of themselves as a "medic" vastly overshadowing any other facets of their identity-a sad irony considering that diversity of interest and understanding makes a good clinician.

Medical training can be confidence-sapping. many of us had felt in school that we were gifted in other areas, but few felt like "natural doctors", if such a thing exists. Suddenly we were faced with the fact that above all we were "medics", but did not feel we had any particular flair for the job. Some of us did not make it through the exams, some left the course: the preclinical years especially were tinged with the dread of being one of the statistics of medical student dropout rates. For many of us, medical school was the first time we had ever worked in fear of failing as opposed to not excelling. Rarely are we given feedback on how we are doing, and passing an exam is a relief, another hoop jumped through, rather than a celebration of achievement. It is only if you fail that you are really noticed. We also become cogs in the machinery of hospital hierarchy, taking the position of "lowest of the low". Stereotypical consultants walk two paces ahead, recognising us not as people but as "pesky students"; praise for good effort or knowledge is handed out far less liberally than snide and discouraging remarks, from medical and nursing staff alike. By the final years, nonmedical friends have graduated from university to high-flying city jobs, world travel and a cosmopolitan existence while we are left slogging for exams. Tinged as we are, with envy and a sense of being left behind, still economically inactive and relatively helpless in the face of human suffering, still given no credit or respect for our hard work, it is easy to understand why disillusionment and a lack of self esteem are commonplace. A medical student has to steel him/ herself against demoralisation, and learn to be a strong individual to survive the rigours of the course.

There have been some efforts to encourage individuality and broaden the educational base of medical students. Special study modules are one opportunity to do this, but are often seen as a burden, another project that has to be completed, another one of the endless hoops through which we must jump. Perhaps replacing these with less pressurised time to explore the medical humanities and ethics might help to keep alive the flame of enthusiasm and compassion which drew so many to medicine in the first place. This might provide a cohort of graduates who are less insular and thereby have more support mechanisms in society.

Leaving medical school, we are very different from how we were on entering. Changes cannot be attributed wholly to the passing of time and increasing maturity, since the pressures of medical school irreversibly influence our personalities. Much flair has been subdued, as we have adapted to fit the medical role and become increasingly isolated as a group. None of us was aware, on applying for medical school, of what the five years would entail. Ravines lie between us as medical students and our final goal of becoming doctors-in the form of academic, social and emotional challenges, dealing with clinical situations, learning to cope with death and illness and fulfilling that which is expected of us as medical students. To cross those ravines, we must adapt. In "becoming medics", it is essential that we be allowed and encouraged by our training to develop personally, as interesting and interested individuals. Thus we can enter the medical profession enriched and motivated: as better, happier doctors.

Sarah Elise Finlay and Monica Fawzey are medical students at The University of Bristol.

\section{References}

1 Pickard M, Bates L, Dorian M, Greig H, Saint D. Alcohol and drug use in second year medical students in the University of Leeds. Medical Education 2000;34:86-7.

2 Anatomy Act 1984 s 3 (3)(6). London: HMSO, 1984.

3 www.mps.org.uk 